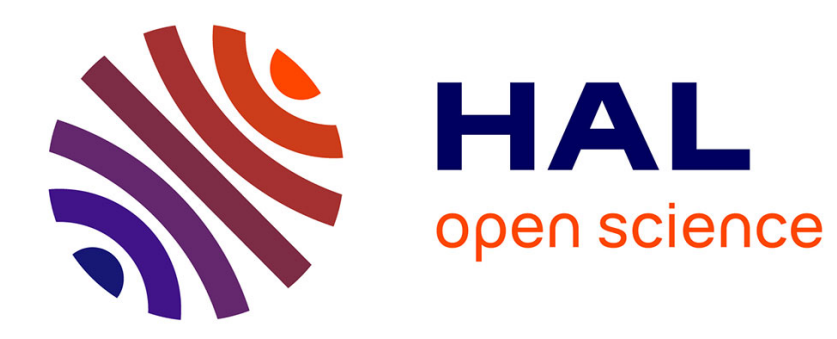

\title{
Collisional relaxation of highly excited vibrational levels of $\mathrm{I} 2(\mathrm{X})$
}

\author{
M. Nowlin, M. Heaven
}

\section{To cite this version:}

M. Nowlin, M. Heaven. Collisional relaxation of highly excited vibrational levels of I2(X). Journal de Physique IV Proceedings, 1994, 04 (C4), pp.C4-729-C4-737. 10.1051/jp4:19944202 . jpa-00252664

\section{HAL Id: jpa-00252664 https://hal.science/jpa-00252664}

Submitted on 1 Jan 1994

HAL is a multi-disciplinary open access archive for the deposit and dissemination of scientific research documents, whether they are published or not. The documents may come from teaching and research institutions in France or abroad, or from public or private research centers.
L'archive ouverte pluridisciplinaire HAL, est destinée au dépôt et à la diffusion de documents scientifiques de niveau recherche, publiés ou non, émanant des établissements d'enseignement et de recherche français ou étrangers, des laboratoires publics ou privés. 


\title{
Collisional relaxation of highly excited vibrational levels of $I_{2}(X)$
}

\author{
M.L. NOWLIN and M.C. HEAVEN \\ Department of Chemistry, Emory University, Atlanta, GA 30322, U.S.A.
}

\begin{abstract}
The relaxation dynamics of vibrationally excited levels of $I_{2}(X)$ are of relevance to the chemical oxygen iodine laser. We have investigated relaxation of $I_{2}\left(v^{\prime \prime}>20\right)$ by pulsed laser techniques. Individual ro-vibrational levels were populated by stimulated emission pumping. Collisionally populated levels were monitored via laser excitation of the D-X transition. Preliminary rate constants for vibrational relaxation of $I_{2}\left(v^{\prime \prime}>20\right)$ by Ar and $\mathrm{H}_{2} \mathrm{O}$ are reported. Improved spectroscopic constants for the D state are also presented.
\end{abstract}

\section{Introduction.}

At present, the Chemical Oxygen Iodine Laser (COIL) is the only demonstrated example of a chemically pumped electronic transition laser ${ }^{1,2}$. In this device chemically generated $\mathrm{O}_{2}{ }^{1} \Delta$ dissociates molecular iodine and excites the atoms to lasing by sequential processes. The mechanism by which $\mathrm{I}_{2}$ is dissociated in this laser has been the subject of many investigations ${ }^{3-10}$, and some controversy. Even now, the mechanism is not fully understood. As $\mathrm{O}_{2}\left({ }^{1} \Delta\right)$ does not posses sufficient energy to dissociate $\mathrm{I}_{2}$ in a single transfer event, multiple collisions must be involved. Current theories identify, as a possible first step, the electronic to vibrational energy transfer $(E-V)$ process 4,6

$$
\mathrm{I}_{2}(\mathrm{X})+\mathrm{O}_{2}\left({ }^{1} \Delta\right) \rightarrow \mathrm{I}_{2}\left(\mathrm{X}, \mathrm{v}^{\prime \prime} \approx 33-44\right)+\mathrm{O}_{2}\left({ }^{3} \Sigma^{-}\right)
$$

Subsequent collisions of $\mathrm{O}_{2}\left({ }^{1} \Delta\right)$ with $\mathrm{I}_{2}\left(\mathrm{X}, \mathrm{v}^{\prime \prime}>20\right)$ can result in direct dissociation, or electronic excitation of $I_{2}$ to the $A^{\prime}\left(2_{u}\right), A\left(1_{11}\right)$, or $B\left(0_{u^{+}}\right)$states ${ }^{4-11}$. There are then several channels, generalized by the equation

$$
\mathrm{O}_{2}\left({ }^{1} \Delta\right)+\mathrm{I}_{2}{ }^{*} \rightarrow 2 \mathrm{I}\left({ }^{2} \mathrm{P}_{3 / 2}\right)+\mathrm{O}_{2}\left({ }^{3} \Sigma^{-}\right)
$$

that can contribute to the dissociation $4-11$. Here, $I_{2}{ }^{*}$ denotes vibrationally $\left(v^{\prime \prime}>20\right)$ or electronically excited (A', A, or B state) $I_{2}$. Once atomic $I$ is liberated it is rapidly excited by the process

$$
\mathrm{I}\left({ }^{2} \mathrm{P}_{3 / 2}\right)+\mathrm{O}_{2}\left({ }^{1} \Delta\right) \rightarrow \mathrm{I}\left({ }^{2} \mathrm{P}_{1 / 2}\right)+\mathrm{O}_{2}\left({ }^{3} \Sigma^{-}\right)
$$

In addition to being the species responsible for lasing, there is good evidence that $I\left({ }^{2} P_{1 / 2}\right)$ participates in the dissociation via the reactions 4,5

$$
\mathrm{I}\left({ }^{2} \mathrm{P}_{1 / 2}\right)+\mathrm{I}_{2}(\mathrm{X}) \rightarrow \mathrm{I}_{2}\left(\mathrm{X}, \mathrm{v}^{\prime \prime} \approx 33-44\right)+\mathrm{I}\left({ }^{2} \mathrm{P}_{3 / 2}\right)
$$

and

$$
\mathrm{I}\left({ }^{2} \mathrm{P}_{1 / 2}\right)+\mathrm{I}_{2}{ }^{*} \rightarrow 3 \mathrm{I}\left({ }^{2} \mathrm{P}_{3 / 2}\right)
$$


The presence of $\mathrm{I}_{2}{ }^{*}$ in $\mathrm{I}_{2} / \mathrm{O}_{2}\left({ }^{1} \Delta\right)$ mixtures has been confirmed by recording chemiluminescence $4,6,10$ and laser induced fluorescence (LIF) spectra6,8,9,11. Populations in the $\mathrm{B}$ and $\mathrm{A}$ states were readily observed via the $\mathrm{B} \rightarrow \mathrm{X}$ and $\mathrm{A} \rightarrow \mathrm{X}$ transitions. For example, Cerny et al. ${ }^{10}$ recently used chemiluminescence to characterize the steady-state rovibrational population distributions in the $A$ and $B$ states. The presence of population in the non-fluorescing $I_{2}\left(A^{\prime}\right)^{9}$ and $I_{2}\left(X, v^{\prime \prime}>20\right)^{6,8,11}$ states has been detected using LIF.

In probing the dissociation of $\mathrm{I}_{2}$ by $\mathrm{O}_{2}\left({ }^{1} \Delta\right)$, it is of obvious value to show that $I_{2}\left(X, v^{\prime \prime}>20\right), I_{2}\left(A^{\prime}\right), I_{2}(A)$, and $I_{2}(B)$ are present in $I_{2} / O_{2}\left(a^{1} \Delta\right)$ mixtures. Unfortunately, this is not sufficient to determine the mechanism. For this purpose, measurements of the rates at which these states are populated and depleted are needed. The present work is primarily concerned with the relaxation dynamics of $I_{2}\left(X, v^{\prime \prime}>20\right)$. A data base for the rates at which various species deactivate $I_{2}(X, v ">20)$ is an essential pre-requisite for realistic models of the dissociation mechanism and laser performance 2,7 . Beyond mechanistic elucidation, measurements of energy transfer rate constants can be used to identify undesirable species in the laser, and facilitate the development of strategies for their minimization or removal.

At this time, little is known about the relaxation rates for highly excited levels of $I_{2}(X)$. Hall et al. ${ }^{5}$ used reaction (4) to generate vibrationally excited $I_{2}$, and they obtained rate constants for vibrational relaxation of $v^{\prime \prime}=40$ by $\mathrm{He}$ and Ar. Abramson et al. 12 demonstrated that the relaxation dynamics could be studied using stimulated emission pumping (SEP) techniques, but they did not determine rate constants. More recently, the authors $^{13}$ used SEP state preparation, and LIF probing techniques to examine the collisional relaxation dynamics of $I_{2}\left(X, v^{\prime \prime}=42, J "=17\right)$. We now report measurements made by selectively populating the levels $\mathrm{v}^{\prime \prime}=38, \mathrm{~J}^{\prime \prime}=49$, and $\mathrm{v}^{\prime \prime}=23, \mathrm{~J}^{\prime \prime}=57$. As in the flow-tube studies of Crozet et al. ${ }^{8}$, and our previous SEP/LIF measurements ${ }^{13}$, we have used the D-X transition to detect population in ro-vibrationally excited levels. There are definite advantages to using the $D-X$ transition, rather than the more familiar $B-X$ system, for this purpose. The D-X transition is much more intense than the $B-X$, the shorter $D$ state lifetime $(\approx 10 \mathrm{~ns})$ renders it less susceptible to collisional quenching, and the fluorescence is spectrally well-removed from B-X and A-X emissions. However, in the course of the present work we found that the existing electronic term energy and vibrational constants ${ }^{14}$ 18 for the D state did not accurately predict the band origins of transitions terminating on the $\mathrm{D}, \mathrm{v}^{\prime}<50$ levels. Consequently, we also report a re-analysis of the low energy levels of $I_{2}$ (D). 


\section{Experimental}

Conceptually, the technique used to study ro-vibrationally excited levels of $I_{2}(X)$ was straightforward ${ }^{13}$. Pulsed lasers were used to excite a single ro-vibrational level of $I_{2}(X)$ by SEP. After a suitable delay, molecules in the initially excited level, and in levels populated by collisions, were detected by a third laser that excited the $D-X$ transition. A small monochromator $(0.25 \mathrm{~m})$ was used to selectively detect the D-X fluorescence.

Two slightly different experimental configurations were employed. Figure 1 shows the apparatus used for measurements involving initial excitation of the level $v^{\prime \prime}=38, \mathrm{~J}=49$. An Nd/YAG pumped dye laser system was used to generate both the pump and dump pulses. The pump laser $\left(0.05 \mathrm{~cm}^{-1}\right.$ linewidth) was tuned to the $\mathrm{B}-\mathrm{X}, 7-2, \mathrm{R}(47)$ line. This transition was chosen because the $1064 \mathrm{~nm}$ fundamental from the Nd/YAG laser could then be used to stimulate down on the 7-38, $\mathrm{P}(49)$ line. An optical delay was used to separate the pump and dump pulses by approximately $10 \mathrm{ns.} \mathrm{A} \mathrm{frequency} \mathrm{doubled} \mathrm{dye} \mathrm{laser,}$ operated with an intra-cavity etalon, was used to observe ro-vibrationally excited $\mathrm{I}_{2}(\mathrm{X})$. Absolute wavenumber calibration of this probe laser was achieved by directing a portion of the fundamental through an $\mathrm{I}_{2}$ cell, and recording the B-X spectrum (c.f. Figure 1). The wavenumbers for the B-X lines were taken from the atlas of Gerstenkorn and Luc ${ }^{19}$.

For the measurements on $\mathrm{v}^{\prime \prime}=23, \mathrm{~J}=57$, an additional laser was added to the system shown in Figure 1. This was used to excite the B-X, 19-1, R(55) line. The $\mathrm{Nd} / \mathrm{YAG}$ pumped dye laser was then used to stimulate down on the 19-23, $\mathrm{P}(57)$ line. Triggering of the lasers was controlled so that the excitation and stimulation pulses were separated by $20 \mathrm{~ns}$.

\section{Results and Discussion}

i) Re-analysis of the $I_{2}$ D-X System

Due to the Franck-Condon factors, the $\mathrm{I}_{2}(X)$ levels populated by $\operatorname{SEP}\left(v^{\prime \prime}=38\right.$, and 23) were most sensitively monitored by exciting transitions to low vibrational levels of the $\mathrm{D}$ state. For the purpose of characterizing the relevant $\mathrm{D}-\mathrm{X}$ transitions, we recorded spectra under conditions where collisionally populated levels were easily observed. This was done to provide a sufficient range of rotational lines for the determination of accurate rotational constants. Figure 2 shows a typical D-X spectrum.

Spectra were recorded for the D-X bands $12 \geq v^{\prime} \geq 5 \leftarrow v^{\prime \prime}=38$ and $37 \geq v^{\prime} \geq 30 \leftarrow$ $v^{\prime \prime}=23$. Band origins and rotational constants were obtained by fitting the line positions to the expression

$$
v=v_{v^{\prime}, v^{\prime \prime}}+B_{v}^{\prime} J^{\prime}\left(J^{\prime}+1\right)-B_{v}^{\prime \prime} J^{\prime \prime}\left(J^{\prime \prime}+1\right)
$$


(trial fits to an expression that included the centrifugal distortion constants did not yield statistically significant values for these parameters). The lower state rotational constants were found to be in good agreement with those obtained by Bacis et al. ${ }^{20}$ and Tellinghuisen et al. ${ }^{14}$ As these earlier studies of the ground state were of greater precision than our measurements, the final fits to equation (1) were made with the lower rotational constants fixed at the values given by Bacis et al. ${ }^{20}$ This scheme yielded D state rotational constants that were in excellent agreement with the values reported by Ishiwata and Tanaka ${ }^{15}$. Vibrational term energies for the D state were calculated by adding the ground state vibrational energies ${ }^{20}$ to the fitted band origins. The new term energies were compared with energies predicted using the constants of Ishiwata and Tanaka 15 . At $v^{\prime \prime}=34$ the predicted energies were in error by $.36 \mathrm{~cm}^{-1}$. This error increased with decreasing $\mathrm{v}^{\prime \prime}$, reaching a value of $1.77 \mathrm{~cm}^{-1}$ at $\mathrm{v}^{\prime}=5$. Comparisons with energies predicted from the constants of Bartels et al. ${ }^{16}$, and Hoy and Lipson ${ }^{17}$ revealed essentially the same discrepancies.

Ishiwata and Tanaka ${ }^{15}$ noted that their data were most accurate for the range $76 \leq v ' \leq 124$. For these levels they reported that the standard deviation of a global fit was $0.052 \mathrm{~cm}^{-1}$. Therefore, we have combined our data for the lower vibrational levels with Ishiwata and Tanaka's ${ }^{15}$ data for $76 \leq v^{\prime} \leq 124$, to define an improved set of vibrational constants. The vibronic term energies were fit to the standard Dunham expression

$$
T_{v}^{D}=\sum_{n} Y_{n, 0}(v+1 / 2)^{n}
$$

Satisfactory fits were achieved using a fifth order polynomial. The resulting constants are given in Table I, were they are compared with several previous estimates. Local fitting problems are primarily responsible for the differences. The previous constants work well over the ranges of levels from which they were defined. We find that our revised vibrational constants, combined with the rotational constants of Ishiwata and Tanaka 15 , predict the positions of lines associated with the v' $\leq 124$ levels to within $\pm 0.05 \mathrm{~cm}^{-1}$.

\section{ii) Energy Transfer Measurements.}

In order to study rotational and vibrational energy transfer, a small amount of $I_{2}$ (typically 10-25 mTorr) was mixed with 0.5-1 Torr of a collision partner. Probe laser spectra were then recorded for a number of fixed delays between the state preparation and probe laser pulses. The collision partners investigated were $\mathrm{He}, \mathrm{Ar}, \mathrm{O}_{2}$, and $\mathrm{H}_{2} \mathrm{O}$. Self transfer was examined using an $\mathrm{I}_{2}$ pressure of $200 \mathrm{~m}$ Torr. The rate constants for removal of population from the initially prepared level were determined by monitoring the decay of the LIF signal as the delay time was increased ${ }^{13}$. Table 2 lists the total removal rate 
constants for $v^{\prime \prime}=38, J^{\prime \prime}=49$. For comparison, our previous results ${ }^{13}$ for $v^{\prime \prime}=42, J "=17$ are also given.

Analyses of the ro-vibrational energy transfer data are in progress. Preliminary results indicate that the rotational energy transfer dynamics of $v "=23$ and $v "=38$ are very similar to those observed for $v^{\prime \prime}=42^{13}$. Features due to vibrational energy transfer were observed for all collision partners (in our previous work the noise level precluded detection of vibrational transfer induced by $\mathrm{Ar}$ or $\mathrm{I}_{2}$ ). For $\mathrm{v}^{\prime \prime}=23 \rightarrow 22$ transfer induced by Ar we obtained a rate constant of about $3 \times 10^{-11} \mathrm{~cm}^{3} \mathrm{~s}^{-1}$. This is appreciably greater than our earlier upper bound for this rate constant, and the present value is in agreement with the work of Hall et al..$^{5}$ Surprisingly, we found that $\mathrm{H}_{2} \mathrm{O}$ was not particularly effective in removing vibrational energy from $\mathrm{I}_{2}$. To illustrate this point, figure 2 shows a section of the $\mathrm{I}_{2} \mathrm{D}-\mathrm{X}$ spectrum taken in a mixture of 10 mTorr of $\mathrm{I}_{2}$ with 200 mTorr of $\mathrm{H}_{2} \mathrm{O}$. The delay between the dump pulse and probe pulses was $500 \mathrm{~ns}$. Lines originating from levels populated by rotational energy transfer are prominent in this trace. A few weak features produced by $\mathrm{v}^{\prime \prime}=23 \rightarrow 22$ relaxation can also be seen (note that vibrational transfer occurs with very little change in the angular momentum). From spectra recorded at a number of different delays, it could be seen that the population lost from $v_{i}{ }^{\prime \prime}=23, J_{i}{ }^{\prime \prime}=57$ was, within the experimental error limits, accounted for by the population transferred to other $v "=23$ rotational levels and $v^{\prime \prime}=22$. Computer modeling of the kinetics yielded a rate constant for $v^{\prime \prime}=23 \rightarrow 22$ transfer induced by $\mathrm{H}_{2} \mathrm{O}$ of $\approx 9 \times 10^{-11} \mathrm{~cm}^{3} \mathrm{~s}^{-1}$. This value is a factor of three smaller that the rate constant for $\mathrm{H}_{2} \mathrm{O}$ deactivation of $\mathrm{I}_{2}(\mathrm{X}, \mathrm{v} \approx \approx 0$ ) estimated by Heidner et $\mathrm{al}^{4}$, and used in COIL system computer models ${ }^{2}$. The actual discrepancy is greater than an order of magnitude, because the deactivation process represents transfer from levels around $v^{\prime \prime}=40$ to levels below $v^{\prime \prime}=20$. As it will take many transfer collisions to achieve deactivation, our results imply that the effective rate constant will be of the order of $10^{-12}$ $\mathrm{cm}^{3} \mathrm{~s}^{-1}$.

A few general trends are suggested by the energy transfer data obtained so far. For the collision partners examined, vibrational relaxation was about an order of magnitude slower than rotational redistribution, and governed by a strong $\Delta v=-1$ propensity. Nonreactive molecular collision partners were no more effective than rare gas atoms in causing vibrational transfer. The primary factor controlling the vibrational transfer probabilities appeared to be the mass of the collision partner; light colliders being most effective in transferring energy. These trends are consistent with vibrational-to-transitional (V-T) energy transfer, and can be explained by classical models 21,22 . Although vibration-tovibration $(\mathrm{V}-\mathrm{V})$ transfer could occur with $\mathrm{O}_{2}$ and $\mathrm{H}_{2} \mathrm{O}$, it seems that the mis-matches between the donor and acceptor frequencies are too great for this to be effective. Even for 
$I_{2}\left(X, v^{\prime \prime}<20\right)+I_{2}(X)$ collisions, where the mis-match in vibrational intervals is less severe, $\mathrm{V}-\mathrm{V}$ transfer does not appear to be of importance.

\section{Acknowledgments}

This work was supported by the Air Force Office of Scientific Research under grant AFOSR-F49620-92-0073.

\section{References.}

1. W. E. McDermott, N. R. Pchelkin, D. J. Benard, and R. R. Bousek, Appl. Phys. Lett. 32,469 (1978).

2. see, S. Churassy, R. Bacis, A. J. Bouvier, C. Pierre dit Mery, B. Erba, J. Bachar, and S. Rosenwaks, J. Appl. Phys. 62, 31 (1987) and references therein.

3. R. G. Derwent and B. A. Thrush, J. Chem. Soc., Faraday Trans. 2, 68, 720 (1972).

4. R. F. Heidner, C. E. Gardner, G. I. Segal, and T. M. El-Sayed, J. Phys. Chem. 87, 2348 (1983).

5. G. E. Hall, W. J. Marienelli, and P. L. Houston, J. Phys. Chem. 87, 2153 (1983)

6. M. H. van Bentham and S. J. Davis, J. Phys. Chem. 90, 902 (1986).

7. D. David, V. Joly, and A. Fausse, "Proceedings of the 7th International Symposium on Gas Flow and Chemical Lasers", pp 156, Springer Proceedings in Physics, Berlin, 1987.

8. P. Crozet, R. Bacis, A. Bouvier, A. J. Bouvier, S. Churassy, and J. P. Pique, J. Phys. C48, 385 (1987).

9. M. Nota, A. J. Bouvier, R. Bacis, A. Bouvier, P. Crozet, S. Churassy, and J. B. Koffend, J. Chem. Phys. 91, 1938 (1989).

10. D. Cerny, R. Bascis, A. J. Bouvier, S. Poulat, A. Topouzkhanian, and J. Vergès, J. Quant. Spectrosc. Radiat. Transfer, 47, 9 (1992).

11. A. J. Bouvier, R. Bacis, A. Bouvier, D. Cerny, S. Churassy, P. Crozet, and M. Nota, J. Quant. Spectrosc. Radiat. Transfer, 49, 311 (1992)

12. E. Abramson, H.-L. Dia, R. W. Field, D. G. Imre, J. L. Kinsey, C. Kittrell, D. E. Reisner, and P. H. Vaccaro. "Conference on Lasers as Reactants and Probes in Chemistry", pp 23, Editors, W. M. Jackson and A. B. Harvey, Howard University Press, 1985.

13. M. L. Nowlin and M. C. Heaven, J. Chem. Phys. 99, 5654 (1993)

14. J. Tellinghuisen, M. R. McKeever, and A. Sur, J. Mol. Spectrosc. 82, 225 (1980)

15. T. Ishiwata and I. Tanaka, Laser Chem. 7, 79 (1987)

16. M. Bartels, R. J. Donovan, A. J. Holmes, P. R. R. Langridge-Smith, M. A. MacDonald, and T. Ridley, J. Chem. Phys. 91, 7355 (1989)

17. A. J. Hoy and R. H. Lipson, Chem. Phys. 140, 187 (1990)

18. J. Tellinghuisen, Chem. Phys. Lett. 29, 359 (1974)

19. S. Gerstenkorn and P. Luc, "Atlas du Spectre d'Absorption de la Molécule d'Tode," Laboratoire Aime Cotton, CNRS II, Orsay, France, 1977.

20. R. Bacis, D. Cerny, and F. Martin, J. Mol. Spectrosc. 118, 434 (1986)

21. D. J. Nesbitt and J. T. Hynes, Chem. Phys. Lett. 82, 252 (1981).

22. D. J. Nesbitt and J. T. Hynes, J. Chem. Phys. 76, 6002 (1982). 
Table 1

Electronic Term Energies and Vibrational Constants for $I_{2}(D)\left(\mathrm{cm}^{-1}\right)$

\begin{tabular}{|c|c|c|c|c|c|}
\hline Constant & $\begin{array}{l}\text { Present } \\
\text { work. }\end{array}$ & Ref. (18) & Ref. (15) & Ref. (16) & Ref. (17) \\
\hline $\mathrm{Y}_{00}\left(\mathrm{~T}_{\mathrm{e}}\right)$ & $41026.31(5)$ & $41026.4(4)$ & $41028.584(47)$ & $41028.584(47)$ & $41028.542(72)$ \\
\hline$Y_{01}\left(\omega_{e}\right)$ & $95.0952(4)$ & $95.66(21)$ & $94.9928(60)$ & $95.0108(286)$ & $94.99697(1149)$ \\
\hline$Y_{02}\left(-\omega_{e} x_{e}\right)$ & $-0.11104(2)$ & $-0.1345(50)$ & $-0.10919(26)$ & $-0.11008(155)$ & $-0.108789(590)$ \\
\hline$Y_{03} / 10^{-4}$ & $-5.639(3)$ & $-2.14(43)$ & $-5.805(50)$ & $-5.759(310)$ & $-6.1458(1378)$ \\
\hline $\mathrm{Y}_{04 / 10^{-6}}$ & $3.612(3)$ & $1.3(2)$ & $3.686(43)$ & $3.963(287)$ & $4.4999(1706)$ \\
\hline$Y_{05} / 10^{-9}$ & $-7.477(8)$ & $-1.7(2)$ & $-7.61(13)^{b}$ & $-1.122(124)$ & $-1.5718(1194)$ \\
\hline $\mathrm{Y}_{06} / 10^{-11}$ & - & - & - & $1.367(204)$ & $3.289(474)$ \\
\hline$Y_{07} / 10^{-14}$ & - & - & - & - & $-3.64(1.00)$ \\
\hline $\mathrm{Y}_{08} / 10^{-17}$ & - & - & - & - & $1.30(86)$ \\
\hline
\end{tabular}

Table 2

Rate Constants for Population Loss from Individual Ro-vibrational Levels of $I_{2}(X)$

\begin{tabular}{lcc}
$\begin{array}{l}\text { Collision } \\
\text { partner }\end{array}$ & \multicolumn{2}{c}{$\mathrm{k} / 10^{-10} \mathrm{~cm}^{3} \mathrm{~s}^{-1}$} \\
\cline { 2 - 3 } $\mathrm{v}^{\prime \prime}=38, \mathrm{~J}^{\prime \prime}=49 \mathrm{a}$ & $\mathrm{v} "=42, \mathrm{~J}^{\prime \prime}=17^{\mathrm{a}}$ \\
$\mathrm{He}$ & 4.6 & 6.6 \\
$\mathrm{Ar}$ & 5.7 & 5.0 \\
$\mathrm{I}_{2}$ & 6.6 & 8.6 \\
$\mathrm{O}_{2}$ & 7.5 & 7.8 \\
$\mathrm{H}_{2} \mathrm{O}$ & 9.1 & -
\end{tabular}

a. Error limits are $\pm 0.5 \times 10^{-10} \mathrm{~cm}^{3} \mathrm{~s}^{-1}$ 


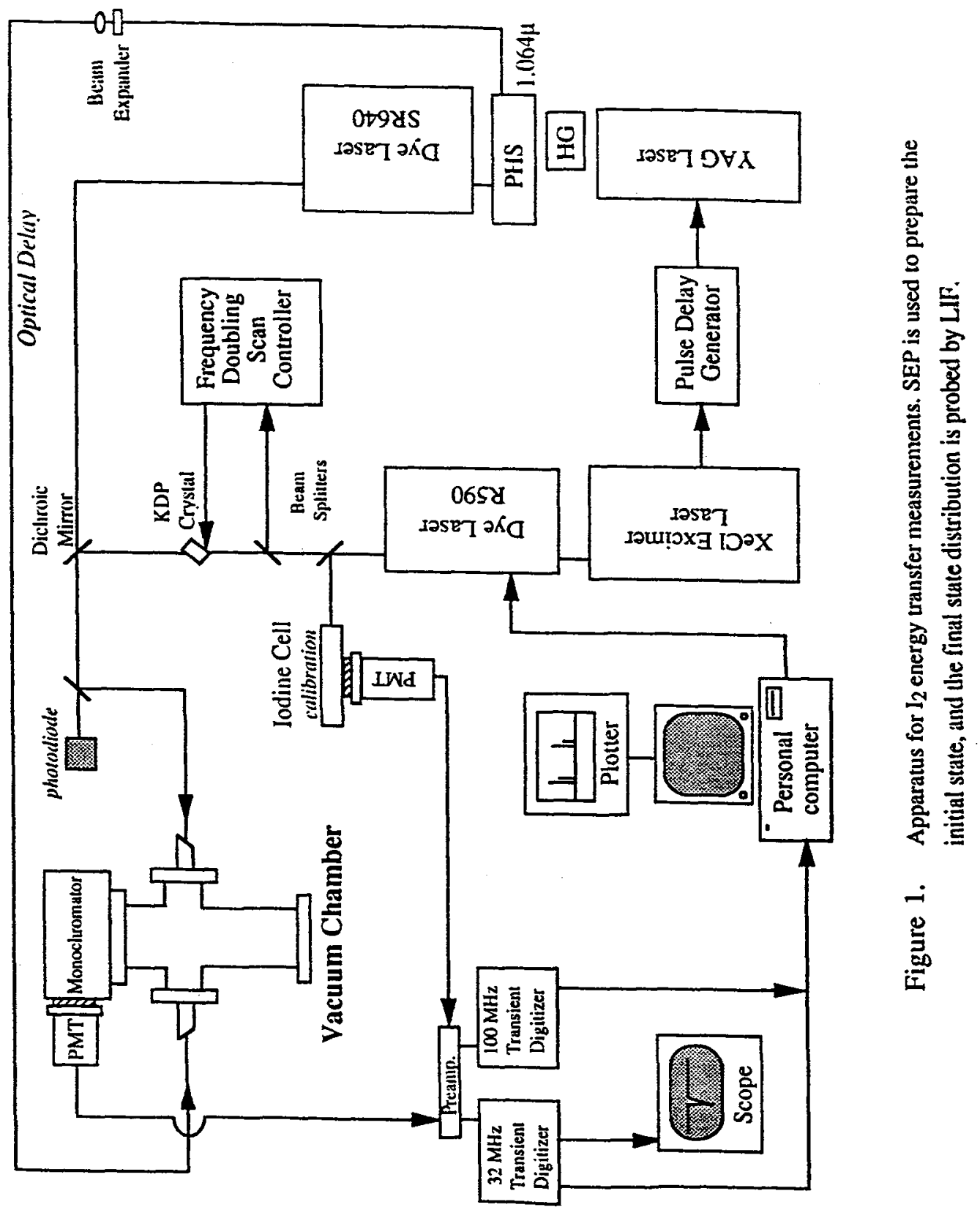




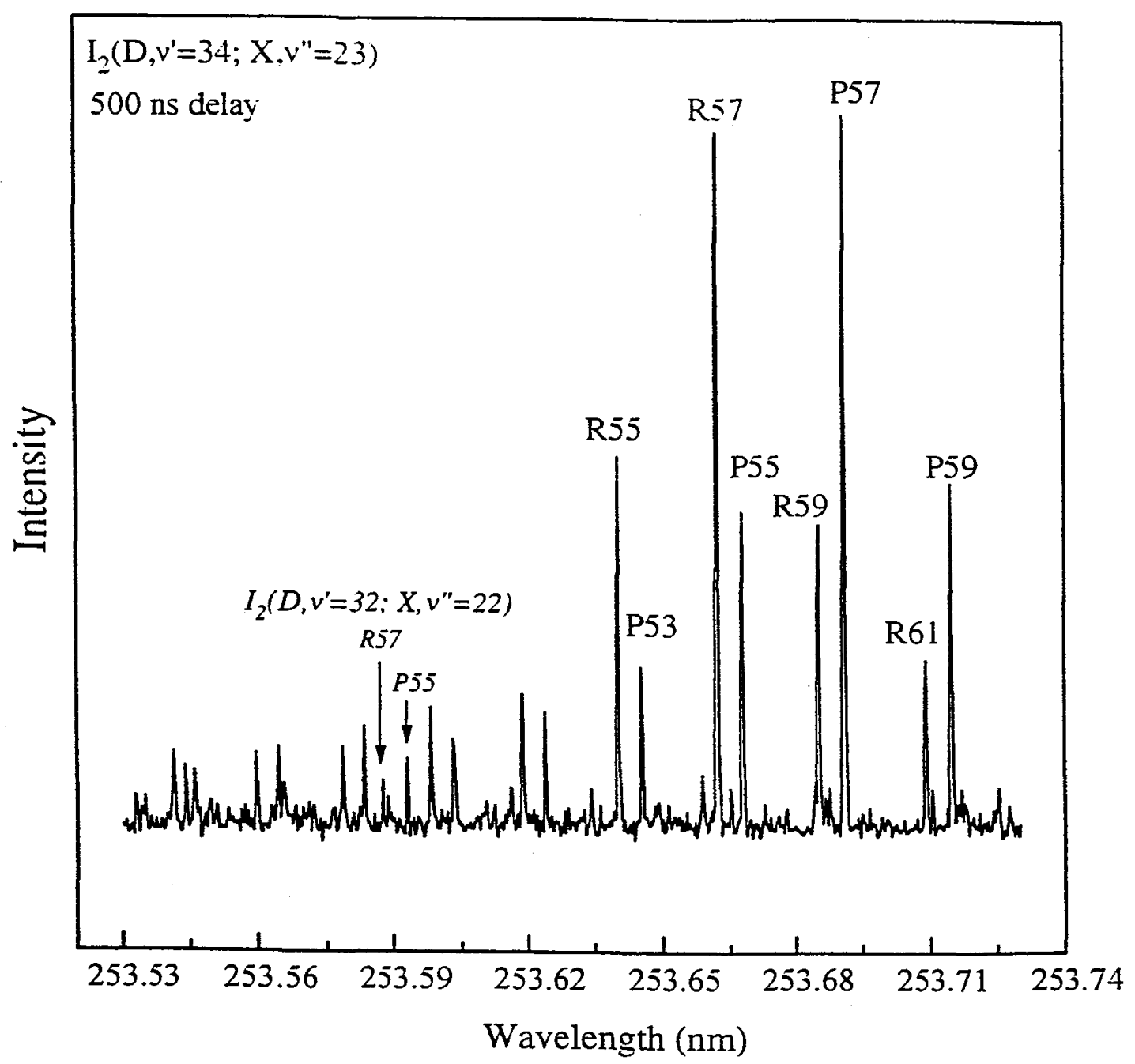

Figure 2. $\quad I_{2}$ D-X spectrum showing energy transfer induced by collisions with $\mathrm{H}_{2} \mathrm{O}$. The initially populated level was $v=23, J=57$. Note that rotational transfer is governed by a $\Delta J=e v e n$ selection rule. Lines originating from collisionally populated $\mathrm{v}=22$ levels are evident near $253.6 \mathrm{~nm}$. 